Ann. Sci. forest., 1972, 29 (3), 391-395.

Note

\title{
ÉTUDE ANATOMIQUE \\ DE LA GREFFE D'UN CHATAIGNIER SUR CHÊNE
}

\author{
R. HEITZ et C. JACQUIOT \\ Centre technique du Bois \\ 10, avenue de Saint-Mandé, Paris $12^{e}$
}

En dehors des particularités anatomiques de la région de raccordement des tissus du sujet et du greffon, la greffe soulève des problèmes d'ordre physiologique. Le premier est la compatibilité entre les tissus des deux végétaux. Le second est la possibilité d'une influence du sujet sur le greffon. Ces deux points ont donné lieu à de nombreuses études, notamment en ce qui concerne la greffe des arbres fruitiers, dans laquelle on constate souvent une action quantitative et qualitative du sujet sur la fructification.

Un troisième problème est apparu avec le développement des recherches sur les cultures in vitro de tissu cambial de divers arbres. Le cambium ainsi isolé de la cime prolifère en formant des masses de tissu dépourvu d'organisation, souvent réduit à un parenchyme non lignifié, englobant parfois chez certaines espèces des vaisseaux du type spécifique normal.

Des recherches approfondies dans lesquelles ont été comparées la structure du tissu formé par le cambium en culture et les structures des tissus néoformés par le cambium in situ, mais privé d'une manière quelconque de ses liaisons avec la cime (cambium de la souche d'un arbre coupé (fig. 1), ou d'un billon dépourvu de rameaux feuillés et placé dans l'eau) ont montré que la structure de ces tissus est identique dans les trois cas (5).

Ces résultats conduisaient à envisager l'hypothèse de l'existence de facteurs d'organisation provenant des bourgeons ou des pousses et indispensables à la formation de tissus ligneux normaux Certaines expériences de greffes de bourgeons sur un tissu en culture ont effectivement permis d'obtenir la réapparition de cellules lignifiées normales $(2,4,5,7)$. Il s'agissait alors de bourgeons de a même espèce végétale.

Par ailleurs, l'observation courante des arbres greffés montre que le sujet forme un bois de structure normale ce qui donne à penser que les facteurs hypothétiques envisagés peuvent être actifs sur une variété, voire une espéce différente de celle du greffon. La greffe de châtaignier sur chêne offre un exemple très caractéristique de greffe intergénérique de deux espèces dont le bois présente des différences anatomiques marquées.

Des greffes de ce type avaient été réalisées dans le courant du siècle dernier au jardin botanique de Dijon. Les notes léguées par le regretté Directeur Philibert GuiniER, Membre de l'Institut, nous ont permis, avec 1'obligeant concours de M. Pornsot, Directeur du Jardin Botanique de Dijon, de réunir la bibliographie concernant l'historique des greffes de châtaignier sur d'autres essences, en particulier sur chêne pédonculé ou sur chêne-liège. BAUDOT (1) signale que les greffes de châtaignier 


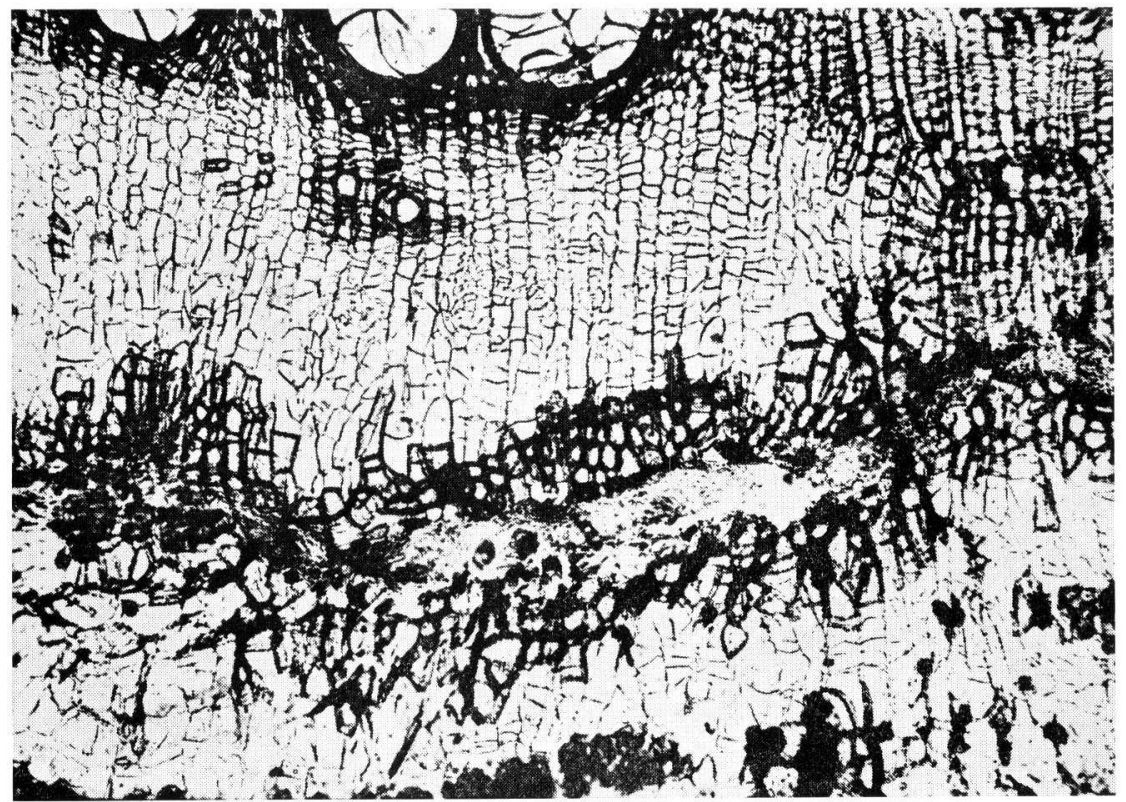

FIG. 1. - Coupe transversale des tissus périphériques prélevés en novembre de la souche d'un chêne abattu en juin. X 100

Aux tissus ligneux normaux, présentant les caractères particuliers du bois initial, formé avant l'abattage de l'arbre, succède une zone de tissu inorganisé, non lignifié, englobant des îlots irréguliers de cellules lignifiées plus ou moins aberrantes

FIG. 1. - Cross section in the outer layer of tissues, excised in November, from the stump of an oak felled in June. X 100

The normal woody tissues, showing the features of early wood, formed before the felling of the tree, are followed by an unorganized unlignified parenchyma, with interspersed inlets of more or less abnormal lignified cells

sur des sujets d'autres essences étaient sans doute déjà connues dans l'antiquité et cite à ce propos deux vers des Géorgiques (chant II, vers 71 et 72 ) concernant la greffe du châtaignier sur hêtre :

«Castaneae fagus, ornusque incanuit albo »

"Flore piri, glandemque sues fregere sub ulmis. »

Pour une époque plus proche de nous, BAUDOT cite une phrase du Théâtre d'Agriculture (paru en 1600) d'Olivier DE Serres

«Aucuns entent le chastagnier sur le chesne, où il se reprend »...

De même l'abbé DE SAUVAGES aurait réussi vers le milieu du $18^{\mathrm{e}}$ siècle des greffes de châtaignier sur chêne. D'après DHOMBREs certains de ces arbres produisaient des châtaignes alors que des rameaux gourmands de chêne poussaient sur le tronc (3). Il semble que ces tentatives très anciennes avaient pour objet d'obtenir la production de châtaignes dans des stations à roche-mère calcaire, impropres au châtaignier, essence nettement calcifuge.

Le châtaignier-chêne de Dijon a été obtenu par une greffe réalisée en 1839 par MeLINE jardinier en chef du jardin botanique de Dijon suivant la technique décrite en détail par WeBER (6) : un sujet de chêne pédonculé (Quercus pedunculata Ehr.) obtenu par semis en 1835 et âgé de 4 ans, avait été greffé en fente à $40 \mathrm{~cm}$ au-dessus du sol avec un greffon de châtaignier. D'après le même auteur, cet arbre avait déjà atteint en 1867 une circonférence de $1 \mathrm{~m}$.

Il vécut jusqu'en 1946, date à laquelle il fut abattu.

M. Poinsot avait remis au Directeur Ph. GuinIER un échantillon du trone de cet arbre prélevé au niveau de la greffe (fig. 2). L'un de nous (5) avait procédé à l'étude anatomique du bois à ce niveau. 
Cette étude a montré que le bois du sujet présente les caractères normaux du bois de chêne : l'examen macroscopique montre déjà que l'aubier du sujet est plus large que celui du greffon, différence normale entre le chêne, chez lequel l'aubier comprend en général une vingtaine de couches annuelles,

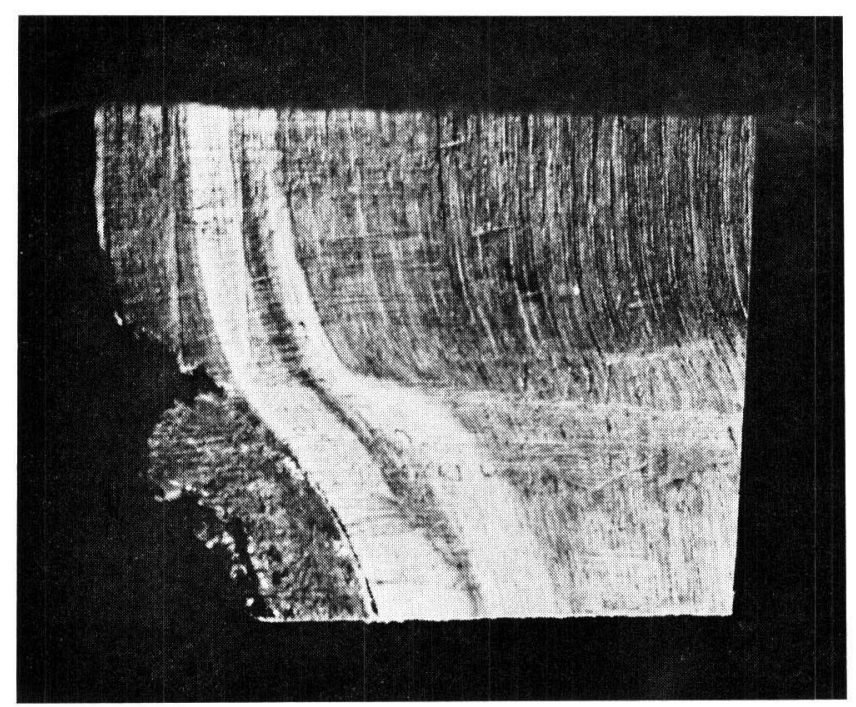

FIG. 2. - Échantillon du bois du châtaignier-chêne de Dijon, prélevé au niveau de la greffe. Noter la différence de largeur de l'aubier dans le sujet (en bas) et dans le greffon, ainsi que la continuité du "fil du bois "

FIG. 2. -- Sample of wood from the chestnut-oak of Dijon, excised at graft level - Notice the difference in width of sapwood in the stock (bottom) and in the scion, as well as the undisturbed grain

et le châtaignier, dont l'aubier est formé seulement de trois ou quatre couches. La vitesse de croissance en diamètre du chêne étant inférieure à celle du châtaignier, le diamètre du greffon au-dessus de la greffe est notablement supérieur à celui du sujet. Au niveau de la greffe, les éléments longitudinaux du bois du sujet s'incurvent vers l'extérieur, ceux du greffon vers l'intérieur, de telle sorte que la continuité du « fil du bois » est maintenue, le niveau de raccordement des cellules des deux essences correspondant à un point d'inflexion dans le tracé du fil. Cette continuité est nettement visible à l'examen anatomique (fig. 3), le passage d'un tissu à l'autre n'étant marqué par aucune discontinuité ni aucune brisure des files longitudinales de cellules, mais seulement par la succession du plan ligneux caractéristique du châtaignier, à rayons ligneux tous unisériés, rarement bisériés, à celui du chêne, où coexistent des rayons unisériés et des rayons multisériés. Ces derniers se manifestent à l'examen visuel d'une section radiale par la présence des « maillures », absentes chez le châtaignier.

En ce qui concerne les vaisseaux, les anastomoses entre chêne et châtaignier ne pouvaient fournir des données bien nettes car les chênes à feuilles caduques et le châtaignier ont une disposition des vaisseaux très analogue : zone poreuse avec une disposition des vaisseaux du bois final tendant vers un arrangement en zones radiales plus ou moins régulières.

Les ponctuations rayon-vaisseau, plus grandes et allongées chez le châtaignier, peuvent donner une indication, mais la différence est trop peu accentuée pour permettre de trancher avec certitude entre les combinaisons possibles des contacts entre deux éléments pris dans chacune des deux lignes :

$$
\begin{array}{ll}
\text { vaisseau de chêne } & \text { vaisseau de châtaignier } \\
\text { rayon de chêne } & \text { rayon de châtaignier }
\end{array}
$$

et le seul caractère net est la disparition des rayons plurisériés quand on passe du chêne au châtaignier.

La similitude de disposition des vaisseaux dans les deux espèces explique l'absence de brisure à la ligne de soudure des deux tissus. 
De fait, on constate dans les coupes longitudinales que la direction des vaisseaux, comme celle des fibres et des fibres trachéides ne présente pas de discontinuité quand on passe du chêne au châtaignier, sans qu'il soit possible d'affirmer avec certitude la continuité d'un vaisseau considéré indi-

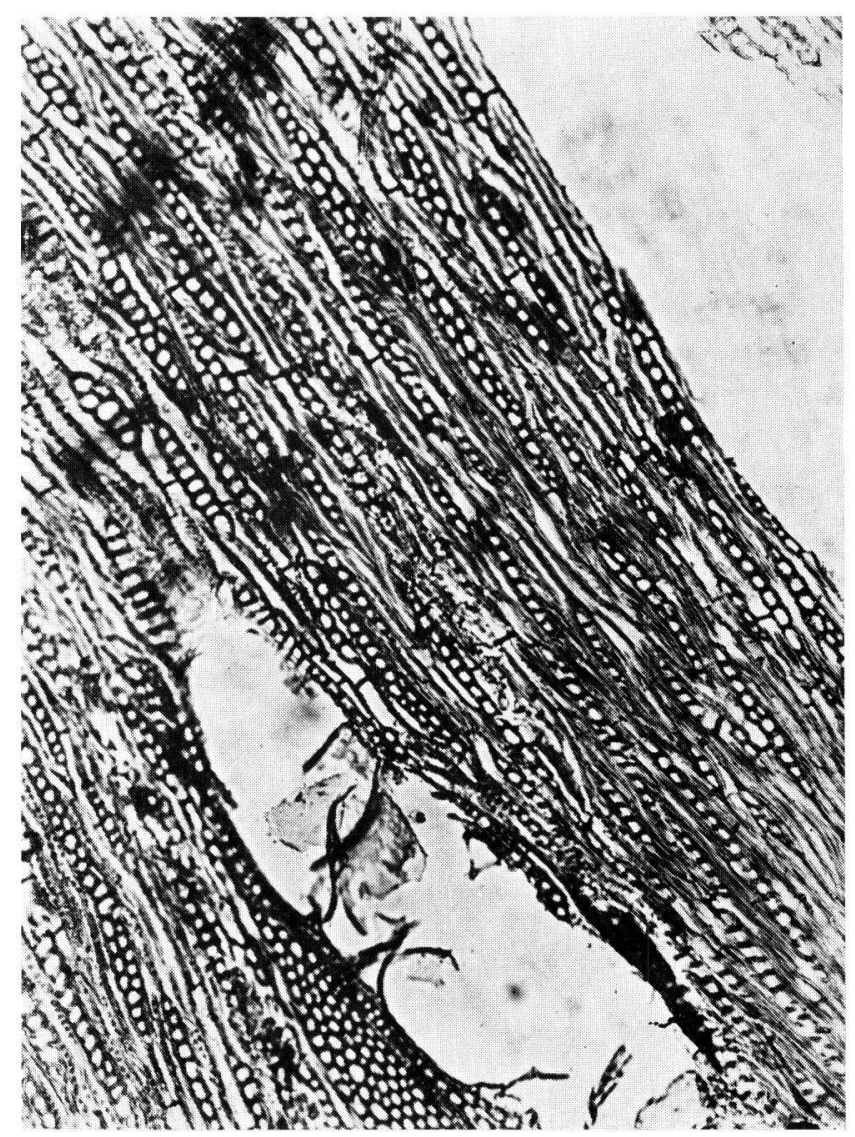

FIG. 3. - Coupe tangentielle au niveau de la greffe. En bas à gauche rayon plurisérié, caractéristique du bois de chêne. En haut présence exclusive de rayons unisériés, parfois partiellement bisériés, caractéristique du bois de châtaignier. $\mathrm{X} 135$

FIG. 3. - Tangential section at graft level. At bottom left multiseriate ray, a caracteristic feature of oak wood. At the top, only uniseriate, occasionnaly biseriate, rays, a normal feature of chestnut wood. X 135

viduellement. Il semble plutôt qu'au-delà de la ligne de démarcation un vaisseau de châtaignier succède avec un faible décalage, mais en gardant la même direction, à un vaisseau de chêne d'un diamètre comparable.

Cet arbre offre ainsi un exemple très typique de greffe intergénétique dans laquelle le bois du sujet a gardé tous ses caractères anatomiques spécifiques et, au point de vue physiologique, a conservé une indépendance qui se traduit par une croissance plus lente et un aubier plus large que chez le greffon.

Ces observations rapprochées des résultats des expériences précédemment citées sur la structure aberrante des tissus formés par le cambium d'arbres écimés ou par le cambium cultivé in vitro, montrent que le sujet a reçu du greffon les facteurs d'organisation permettant à son cambium d'édifier des tissus conformes à sa structure spécifique normale. Cette structure est donc bien déterminée 
exclusivement par des facteurs génétiques mais l'information génétique ne peut opérer qu'en présence de facteurs chimiques non spécifiques, fournis par les organes chlorophylliens du greffon, et dont la manifestation avait conduit au concept de facteurs d'organisation (4).

Reçu pour publication en mai 1972.

\section{REMERCIEMENTS}

En rédigeant cette note, nous rendons hommage à la mémoire de notre regretté maître $\mathrm{Ph}$. GuiNIER qui nous en avait légué les premiers éléments. Nous adressons nos vifs remerciements à M. Pornsot, Membre de la Société Botanique de France, qui nous a permis de prendre connaissance de publications rares et difficiles à consulter.

\section{SUMMARY}

\section{ANATOMICAL STUDY OF THE GRAFT IN A CHESTNUT TREE GRAFTED ON OAK}

A tree resulting from grafting a chestnut scion on an oak stock in 1839, lived on until 1946. The anatomical structure of its wood at the level of the graft is described. The comparison with the structure of oak cambial tissue cultured in vitro affords evidence that the chestnut scion could supply the cambium of the oak stock with organization factors, necessary for the building up of its normal specific structure.

\section{ZUSAMMENFASSUNG}

zur anatomischen Struktur, auf der Höhe der Propfstellung, des Holzes einer Edelkastanie gepropften auf einer Stieleiche Unterlage

In 1839 ein Edelreis von Edelkastanie war auf einer Stieleiche Unterlager gepropft worden. Dieser Propfling lebte bis 1946. Die anatomische Struktur des Hölzes auf der Hohe der Propfstellung wird beschrieben. Das Vergleichen mit der Struktur des Kambiumgewebes gezüchteten in vitro weist hin dass der Kastanie Edelreis Organisation Stoffe der Eicheunterlagen liefern Konnte.

\section{RÉFÉRENCES BIBLIOGRAPHIQUES}

1. Baudot A. Le Châtaignier-chêne du Jardin Botanique de Dijon. Bull. Sci. pharmacol., 14, (janvier 1907), p. 4-11.

2. Camus G. 1949. Recherches sur le rôle des bourgeons dans les phénomènes de morphogenèse. Rev. Cytol. Biol. vég., 11, p. 1-199.

3. Dhombres Ch. Bull. Soc. Agricult. de l'Hérault 1938, p. 380.

4. JACQuiot C. 1957. Sur l'existence de facteurs d'organisation des tissus secondaires chez certains arbres forestiers. C. R. Ac. Sci., 244, p. 1246-9, 25 février 1957.

5. JACQuiot C. 1964. Application de la technique de culture des tissus végétaux à l'étude de quelques problèmes de la physiologie de l'arbre. Ann. Sci. forest., 21, fasc. 3, 317-465.

6. Weber J.-B. 1867. Châtaignier greffé sur chêne au jardin botanique de Dijon. Bull. Soc. Horticult. Côte d'Or, 1867 , p. $330-3$.

7. Wetmore R.-H. 1957. In Histogenesis in Plant Tissue Cultures. J. Nation. Cancer Institute, $\mathrm{n}^{\circ} 4$, oct. 1957, p. 555-99. 